\title{
PERIGO, CUIDADO, ATENÇÃO: A COMUNICAÇÃO LINGUIISTICA DE RISCO EM ADVERTÊNCIAS DE PRODUTOS
}

\author{
(Danger, Warning, Caution: The Linguistic \\ Communication of Risk in Product Warnings)
}

\author{
Malcolm Coulthard ${ }^{1}$ \\ (University of Birmingham - UK/ \\ Universidade Federal de Santa Catarina - UFSC ) \\ Caroline Hagemeyer ${ }^{2}$ \\ (Universidade Federal de Santa Catarina - UFSC)
}

\begin{abstract}
This article is concerned with Product Warnings. We review what linguists Dumas, Fraser and Shuy have said about the definition and evaluation of Warnings before moving on to examine real world texts. We then analyse in detail a set of Brazilian hair dye warnings in order to see what comprehension problems they create for their Readers and in what ways they are deficient. The article ends with a detailed analysis of a set of warning texts taken from a Canadian court case in which a man was suing a company that manufactured BBQs for compensation after a $B B Q$ exploded causing third degree burns to his son. He claimed that the product warnings were inadequate.
\end{abstract}

1. Professor Emérito na Universidade de Birmingham, bem como na Universidade de Aston, Inglaterra. Recebeu o título de Professor Honoris Causa pela Universidade de Cardiff por seus conhecimentos e atuação em Linguística Forense. Requisitado como perito, já atuou em mais de duzentos casos em tribunais da Irlanda do Norte, Escócia, Hong Kong, Canadá e no Tribunal de Apelação da Inglaterra. É editor fundador da revista Forensic Linguistics e, atualmente, Professor Permanente na UFSC.

2. Mestre em Língua Inglesa e Literatura Correspondente (UFSC) e Doutoranda em Língua Inglesa e Linguística Aplicada pela mesma Universidade. Tem como interesse de pesquisa o estudo da adequação das advertências de produtos. É professora na Faculdade Guairacá e na rede Estadual de Ensino do Paraná. 
Keywords: warnings, adequacy, imagined reader.

\section{RESUMO}

Este artigo tem como foco central as advertências de produtos. Inicialmente, revisamos o que os linguistas Dumas, Fraser e Shuy discutem sobre a definição e avaliação de advertências, para depois examinar textos reais. Nós analisamos detalhadamente uma série de advertências de tintura capilar a fim de verificar os problemas de compreensão que elas criam para seus Leitores e até que ponto elas são deficientes. $O$ artigo termina com uma análise detalhada de uma série de advertências de um caso da corte Canadense onde um homem moveu uma ação judicial para reparação de danos contra a empresa que fabricou o BBQ depois que o BBQ explodiu causando queimaduras de terceiro grau em seu filho. Ele alegou que as advertências eram inadequadas.

Palavras chave: advertência, adequação, leitor imaginado.

\section{Introdução}

Há vários métodos usados pela indústria, para prevenir riscos associados aos produtos e o uso de advertências é um deles. Entretanto, as advertências não devem ser vistas como um substituto de um bom design, que pode extinguir ou diminuir os riscos. Caso não seja possível extinguir todos os riscos, há ainda a possibilidade de treinar os usuários a fim de que sejam capazes de manusear o produto com segurança. Mas este método fica restringido a uma pequena parcela da população. Finalmente, há ainda a possibilidade de construir uma barreira entre o usuário e o perigo como o uso de equipamentos de proteção, entretanto, este método se aplica a poucos produtos (Wogalter, 2006). Somente quando estes métodos forem insuficientes para remover todos os riscos, as advertências são usadas para "informar as pessoas sobre o perigo, assim consequências indesejáveis são evitadas ou minimizadas” (Wogalter, 2006: 03).

A indústria é responsável pelos métodos de prevenção de riscos e é responsabilizada legalmente caso o consumidor sofra algum tipo de lesão ou seus bens sejam danificados. Entretanto, quando 
se trata das advertências, percebemos uma mudança de papel, pois a responsabilidade da prevenção de riscos é transferida para o consumidor. Esta prática parece injusta, principalmente quando as advertências não são claras ou deixam de informar o consumidor sobre os riscos potenciais. O estudo das advertências é investigado por diversas áreas de conhecimento, como a linguística, a linguística forense e a engenharia de fatores humanos. A primeira dedica-se principalmente com a definição e a estrutura de uma advertência, ao passo que as outras duas preocupam-se também com o destinatário e como a mensagem é recebida por ele. Assim, questões como consumidor comum e inteligibilidade entram em cena com o intuito de verificar a eficácia da mensagem. Para isso, as áreas citadas acima buscam em outras fontes subsídios que ajudem a entender os fatores que deixam uma advertência mais compreensível, tais como: análise do discurso, direito, pragmática, sintaxe e léxis.

O objetivo principal deste artigo é mostrar ao leitor a importância de uma linguagem clara e inteligível nas advertências de produtos. Para isso, iniciaremos com a apresentação da definição e da estrutura de uma advertência. Em seguida, discutiremos sucintamente as características que deixam uma advertência eficaz. Depois, passarmos para a análise de três advertências de tintura de cabelo, a fim de verificar a adequação das mesmas. Finalmente, mostraremos um caso em que o professor Coulthard trabalhou como perito recentemente.

\section{Advertência: definição e estrutura}

Qualquer discussão a respeito de advertências esbarra em ambuiguidade e incerteza. Dumas (1992) afirma que "nenhuma disciplina reconhece uma definição clara e precisa de advertência" $(267)^{3}$. Um olhar mais preciso revela que as advertências dividem algumas características com ameaças e promessas. Além disso, estes atos de fala podem ser proferidos de forma direta, indireta ou

3. Esta e outras citações foram traduzidas pelos autores. 
condicional, muitos dependem do contexto, o que contribui para ambiguidade.

Searle (1969) oferece uma análise sistemática das advertências. Para ele, elas referem-se a eventos futuros, quando falantes e ouvintes não estão interessados que estes eventos aconteçam. Ademais, os ouvintes precisam ter razões para acreditar que estes eventos podem acontecer. Sendo assim, qualquer advertência que não possua estas características pode ser considerada falha, como neste exemplo de uma advertência de um maço de cigarros "parar de fumar agora reduz sérios riscos à sua saúde" (Dumas, 1992: 169), pois não menciona evento ruim. Dumas argumenta que ela somente poderia ser considerada uma advertência se o leitor inferisse 'se eu não parar de fumar agora trarei sérios riscos à minha saúde’, caso contrário, ela se assemelharia a uma promessa, uma vez que prediz um resultado positivo.

Fraser (1998), com base em Searle, define advertências comparando-as com promessas e ameaças. Como todas se referem a eventos futuros, ele discute as semelhanças e diferenças em termos de quem é beneficiado e de quem detém o controle, podendo ser o falante ou o destinatário. Advertências são como promessas quando se referem a uma ação que pode beneficiar o destinatário. A diferença entre estes dois atos está em quem executa a ação. No caso das advertências, a ação é normalmente executada pelo destinatário, que pode escolher ou não, executá-la. Já no caso das promessas, a ação é executada pelo falante, que se compromete em executá-la. É neste ponto que promessas e ameaças convergem, pois em ambas o falante está comprometido com a realização da ação. A principal diferença entre elas reside no fato das promessas serem benéficas para o destinatário, ao passo que as ameaças não o são.

Quando o foco é no falante, Fraser afirma que nenhum dos três atos de fala o beneficia. Entretanto, parece-nos pouco provável que o falante, por exercer certo poder sobre o ameaçado, não se beneficie com a troca.

O falante tem o controle do resultado de uma ação quando se trata de ameaças e promessas, ao passo que nas advertências o controle é imprevisível, uma vez que as advertências sobre o clima estão fora 
do controle do falante. Quando se trata do controle do destinatário, algumas incertezas emergem, visto que ele é capaz de controlar o resultado da ação quando advertências, ameaças e promessas são condicionais. Isto é, se o destinatário seguir as exigências do falante, ele controla a troca. Fraser também inclui em sua discussão a intenção do falante. Quando este pretende intimidar o destinatário, temos uma ameaça. Por outro lado, se o falante quer informar o destinatário sobre um evento que pode prejudicar o destinatário, temos uma advertência. Entretanto, qualquer discussão que envolve a intenção de um participante é passível de dúvidas, pois como observado por Coulthard (1985: 19) "nem o ouvinte nem um analista pode ter certeza da intenção do falante porque ela nunca está disponível para avaliação".

Dumas (2010), seguindo Searle, aponta que advertências podem ser categóricas e hipotéticas. A primeira tem o propósito de aconselhar, isto é, informar "ouvintes e leitores de que certos resultados seguirão certos modos de comportamento" (365) como em 'fumar causa câncer de pulmão', enquanto que a segunda implica em um pedido, seguindo a estrutura 'se X, então Y' implicitamente, como em 'usuários crônicos de bebidas alcoólicas podem apresentar um risco aumentado de doenças do fígado caso seja ingerida uma dose maior que a dose recomendada'. Embora o risco seja explícito em ambos os exemplos, o consumidor precisa inferir como evitar o risco.

Tiersma (2002) sugere dois tipos de advertências: imperativa e informativa. A primeira é mais clara em relação à prevenção do perigo, como nesta advertência de tintura de cabelo 'não use para pintar os cílios e sobrancelhas', que conta ao leitor indiretamente que o produto oferece algum tipo risco, entretanto este risco não está explicitado. $\mathrm{O}$ segundo tem a função de informar, isto é, avisar que o produto oferece algum tipo de risco, como nesta advertência de tintura de cabelo 'as colorações podem provocar uma reação alérgica que, em alguns casos, ainda que raros, pode ser grave'. Como podemos perceber, esta é menos clara em relação à prevenção do risco. Assim, nas duas, o leitor precisa inferir algum significado, seja em relação ao risco, ou sobre como evitá-lo. 


\section{Advertência: adequação}

Argumenta Shuy (2008, p. 72) que as advertências "deveriam identificar e descrever a natureza e o perigo do risco. Depois elas deveriam dizer ao leitor como evitá-lo. Finalmente, elas deveriam comunicar estas informações em uma linguagem clara e inteligível”. A questão da inteligibilidade surge nessa definição e retira do consumidor a responsabilidade única de entender uma advertência. Vários exemplos estão disponíveis na literatura da linguística forense que ilustram as características de um texto que podem levar a falta/ dificuldade de compreensão, como por exemplo: complexidade das frases 'este medicamento pode infrequentemente causar sangramentos do estomago ou intestino sérios (raramente fatal)', palavras técnicas 'paracetamol causa danos hepáticos', e palavras pouco familiares 'não use ibuprofeno concomitantemente com álcool'4. Como visto acima, as bulas de remédio parecem ser uma área onde tais características abundam.

A quantidade de informação fornecida em uma advertência é outro fator que merece atenção. É comum encontrar advertências que dão instruções sobre como evitar uma situação perigosa, mas que não informam sobre o risco real, como este aviso em uma escada rolante 'evite pés descalços', ou ainda advertências que informam sobre o risco, com em 'suas sandálias podem ficar presas na saída da escada rolante', mas não direcionam, deixando o usuário com dúvidas a respeito do procedimento correto para usar as escadas rolantes caso esteja com este tipo de sandálias. É bem provável que o usuário ignore o aviso. Além disso, ter as sandálias presas não é o risco mais sério neste caso, há relatos de crianças que tiveram lesões sérias nos pés por terem as sandálias de borracha presas nas escadas. Portanto, a falta de informação reduz significativamente a eficiência de tais advertências.

A advertência de um pacote de pipoca 'cuidado quando abrir, pois o vapor é muito quente' é um exemplo típico de falta de informação que pode levar a problemas de interpretação. Neste caso, o consumidor é informado somente sobre o perigo implicitamente.

4. Estas advertências foram escritas originalmente em português. 
Ele precisa inferir que o vapor é liberado quando o pacote é aberto, e que ele pode queimar não somente as mãos, mas também a face ou qualquer parte do corpo que entre em contato com o vapor. Finalmente, ele precisa inferir como o perigo deve ser evitado. Porém, se o consumidor tiver somente uma vaga ideia do que é vapor e por que ele é perigoso, as chances de haver uma inferência errada devem ser consideradas. Por outro lado, listar muitos riscos tende a diminuir o efeito das advertências ou ainda levar o leitor a subestimar os riscos, especialmente quando riscos mais graves estão misturados com riscos menos graves, visto que eles podem passar despercebidos por leitores menos atentos (Tiersma, 2002), como nesta advertência de cigarro 'fumar causa perda de dentes, mau hálito e câncer de boca'.

Muitas advertências necessitam de certo grau de inferência para serem entendidas, visto que não é possível escrever tudo sobre um dado risco. Entretanto, qualquer dependência de inferência é problemática uma vez que o consumidor pode equivocar-se ao fazê-la. Por exemplo, na advertência "a fumaça de cigarro contém monóxido de carbono" (Dumas, 1992: 269), o consumidor precisa primeiramente saber o que é esta substância, para saber qual é o seu efeito no organismo, para finalmente inferir que ele é prejudicial à saúde. Somente depois disso, ele será capaz de inferir que diante de tal risco, o melhor seria parar de fumar. Mas, se o consumidor não souber o que é monóxido de carbono, ele terá dificuldade em gerir tais inferências.

\section{Palavra sinal}

É consenso que uma advertência deve ser precedida por uma palavra sinal a fim de não somente alertar as pessoas sobre um possível perigo, mas também indicar o nível do perigo. A maioria dos guias de advertências, como ANSI (American National Standards Institute) e SAE (The Society of Automotive Engineers) recomendam o uso de uma palavra sinal, "que é selecionada com base no nível de seriedade do

5. Advertência escrita originalmente em Inglês. 
risco, especificamente, a probabilidade e severidade do risco associado a não seguir a mensagem de segurança” (Hellier \& Edworthy, 2006: 02). Entretanto, não há consenso a respeito do nível de perigo transmitido por cada um.

As palavras sinais mais usadas nos Estados Unidos são: perigo (danger), advertência (warning) e cuidado (caution) (Wogalter, Jarrard \& Simpson, 1994). É possível que tais escolhas sejam influenciadas pelo guia de advertência ANSI-Z535 4 que recomenda o emprego das seguintes palavras e significados:

PERIGO indica uma situação perigosa que, se não evitada, resultará em morte ou ferimento sério.

ADVERTÊNCIA indica uma situação perigosa que, se não evitada, poderia resultar em morte ou ferimento sério.

CUIDADO, com o símbolo de alerta, indica uma situação perigosa que, se não evitada, poderia resultar em um risco menor ou moderado. ATENÇÃO é usada para endereçar práticas não relacionadas a riscos pessoais. (Kundinger, M, 2008: 15).

O mesmo guia ainda sugere o uso de um sinal de alerta, um ponto de exclamação dentro de um triangulo, para referirse a ferimentos pessoais de qualquer risco. Sendo assim, perigo, advertência, e cuidado devem ser precedidos por um sinal de alerta. Após esta breve discussão a respeito da definição e das características que deixam uma advertência mais eficiente, seguiremos para a análise de três advertências de tintura de cabelo.

\section{Análise de texto: tintura de cabelo}

Estima-se que, no Brasil, um quarto da população usa, ou já usou, tinturas capilares (INMETRO, 2012). Infelizmente, há registro de vários casos de consumidores que sofreram danos, alguns graves, causados por estas tinturas. A ouvidoria do INMETRO tem o registro de inúmeros depoimentos de consumidores que sofreram algum tipo de risco após pintarem os cabelos, como nos depoimentos abaixo: 
"Comprei uma tintura de cabelo e quando passei, o cabelo caiu. Estou andando na rua de boné, pois estou com muita vergonha".

"Tenho um amigo cabelereiro que usou uma determinada marca de tintura de cabelo em duas clientes e verificou que ambas tiveram seus cabelos extremamente danificados, inclusive com queda acentuada. Gostaria de saber qual é a possibilidade do Inmetro realizar análise neste tipo de produto".

Muitos consumidores movem ações indenizatórias contra as empresas fabricantes, mas muitas são julgadas improcedentes sob o argumento de que o requerente não seguiu as recomendações que constam na embalagem. As empresas reconhecem que seus produtos oferecem riscos, visto que tais riscos são informados nas advertências. Mas é justamente por isso que as empresas são eximidas da culpa, que é transferida para o consumidor, sob a alegação de que não seguiu as orientações de uso postadas pelo fabricante. Mas, e se o consumidor não entender as advertências? E se elas não forem claras para que o consumidor adote uma medida de segurança? Ou ainda se elas não forem visíveis? Com base nesses questionamentos, vamos analisar três rótulos de tinturas capilares, nomeadas A, B e C. Além disso, vamos ainda verificar as normas estabelecidas pela ANVISA para este tipo de produto. Gostaríamos de ressaltar que as marcas apresentam outras informações além daquelas requeridas pela agência reguladora, entretanto, não nos ateremos a estas.

Notamos, primeiramente, o uso indiscriminado das palavras sinais. As advertências abaixo se referem ao mesmo risco, no entanto cada uma emprega uma palavra sinal diferente.

a) CUIDADO: Contém substâncias passíveis de causar inflamação na pele de determinadas pessoas;

b) Advertências: Os corantes capilares podem provocar reações alérgicas graves ${ }^{6}$;

6. O destaque em negrito faz parte do original. 


\section{c) IMPORTANTE: AS COLORAÇÕES PODEM PROVOCAR UMA REAÇÃO ALERGICA QUE, EM ALGUNS CASOS, AINDA QUE RAROS, PODE SER GRAVE.}

Como mostrado acima, as palavras cuidado e advertência devem ser usadas para sinalizar que um evento que se não for evitado, pode resultar em algum tipo de risco à saúde, o que difere estas duas palavras é o nível de severidade do risco. Portanto, ambas são adequadas para sinalizar algum risco decorrente da tintura de cabelo. Entretanto, a palavra importante não parece ser adequada para esta situação, pois ela é usada para indicar não somente situações adversas, mas também situações que não tem relação alguma com riscos à saúde ou à propriedade.

A ANVISA é o órgão responsável pelas normas de rotulagem de cosméticos no Brasil (RDC n²11/ 2005), que especificam instruções específicas sobre: ingredientes, modo de usar, restrições de uso e como evitar riscos. Para agentes clareadores de cabelo e tinturas capilares, a ANVISA estabelece o uso de seis advertências, sendo que não há a obrigatoriedade de usar as mesmas palavras estipuladas pela ANVISA, salvo em uma delas, ver abaixo:

\section{OUTRAS OBRIGATORIEDADES EXIGIDAS PELOS DECRETOS} 79.094/77 E 83.239/79

7.1 AGENTES CLAREADORES DE CABELOS E TINTURAS CAPILARES: Os rótulos das tinturas e dos agentes clareadores de cabelos que contenham substâncias capazes de produzir intoxicações agudas ou crônicas deverão conter as advertências: "CUIDADO. Contém substâncias passíveis de causar irritação na pele de determinadas pessoas. Antes de usar, faça a prova de toque" (Art.107Decreto 79.094/77).

Como mencionado anteriormente, uma advertência deve primeiramente identificar e descrever o risco e depois informar ao leitor como evitá-lo (Shuy, 2008). É possível observar estes dois componentes na advertência acima, inclusive na mesma ordem. Entretanto, a linguagem utilizada para identificar o risco não é 
corriqueira, 'Contém substâncias passíveis de causar irritação na pele de determinadas pessoas', e pode dificultar o entendimento.

As cinco advertências exigidas pela ANVISA estão nas tabelas (1 a 5) abaixo. Cada tabela mostra inicialmente as informações determinadas pela ANVISA e logo abaixo, como as três marcas transmitem estas informações. Os fabricantes parecem seguir as recomendações estabelecidas pela ANVISA referentes aos conteúdos das advertências, pois nenhuma suprime informações. Há frases exatamente iguais as propostas pela ANVISA ( $3 \mathrm{~A}, 5 \mathrm{~A}$ e $5 \mathrm{~B}$ ), outras com algumas mudanças ( $2 \mathrm{~A}, 2 \mathrm{~B}, 3 \mathrm{~B}, 4 \mathrm{~A}$ e $4 \mathrm{C}$ ) e ainda aquelas onde há acréscimo de informações (2 C, 3 C, 4 B e 5 C).

Observamos quase que exclusivamente direcionamentos sobre como evitar os riscos, porém, os riscos em si são identificados apenas uma vez. Devemos ainda ressaltar que o único risco apontado é o de alergias, mas não é mencionada a gravidade desta alergia. Além disso, de acordo com a ouvidoria do INMETRO, muitos consumidores sofrem com a queda acentuada dos cabelos, mas nem a ANVISA nem os fabricantes fazem menções a este risco. Assim, é possível dizer que faltam informações referentes aos riscos do produto, o que pode levar os consumidores a inferir que os riscos não são graves, pois se fossem, eles seriam identificados na advertência.

$\mathrm{Na}$ Tabela 1, apresentada a seguir, identificamos que um risco é apontado 'pode causar reações alérgicas', assim como as medidas preventivas 'fazer a prova de toque (descrever)'. Porém, somente a marca A descreve a prova de toque nas advertências da embalagem (primárias), as outras direcionam o consumidor para um folheto explicativo ou verso do cartucho (secundárias). Gostaríamos de ressaltar que a marca B faz este direcionamento somente no final, isto é, depois de apresentar todas as advertências. O escritor, neste caso, assume que o consumidor irá ler todas as informações contidas na embalagem, e que ainda faça ligações entre uma informação que está no início e outra que está no final do texto. 


\section{Tabela 1}

\begin{tabular}{|l|l|}
\hline 1) ANVISA & $\begin{array}{l}\text { Pode causar reação alérgica. Fazer a Prova de Toque } \\
\text { (descrever); }\end{array}$ \\
\hline A & $\begin{array}{l}\text { "Antes de usar, faça a prova do toque". (art. 107 - } \\
\text { decreto 79094/77). PROVA DE TOQUE: Aplicar } \\
\text { uma pequena quantidade do produto preparado na } \\
\text { pele de trás da orelha ou do antebraço. Aguardar o } \\
\text { tempo de ação e enxaguar. Se após 48 horas não } \\
\text { existirem sinais de irritação ou vermelhidão, o produto } \\
\text { poderá ser aplicado; }\end{array}$ \\
\hline B & \begin{tabular}{l} 
Advertências: Os corantes capilares podem provocar \\
reações alérgicas graves. Recomenda-se uma prova \\
preliminar de sensibilidade/ prova de toque. Prova de \\
toque e demais informações, vide verso do cartucho \\
(final do texto). \\
\hline IMPORTANTE: AS COLORAÇÕES PODEM \\
PROVOCAR UMA REAÇÃO ALERGICA QUE, \\
EM ALGUNS CASOS, AINDA QUE RAROS, \\
PODE SER GRAVE. É OBRIGATÓRIO EM \\
TODOS OS CASOS FAZER UMA PROVA DE \\
TOQUE (TESTE DE ALERGIA CUTÂNEA), \\
IMPRETERIVELMENTE 48HORAS ANTES DE \\
CADA UTILIZAÇÃO DESTRE PRODUCTO (VER \\
FOLHETO EXPLICATIVO).
\end{tabular} \\
\hline
\end{tabular}

$\mathrm{Na}$ Tabela 1, percebemos também que a escolha lexical pode afetar o entendimento das mensagens. Em B e C, o escritor escolheu as palavras corantes capilares e colorações para substituir tinturas capilares. No entanto, esta substituição pode gerar confusão, pois alguns leitores podem não associar estas escolhas aos produtos. Outro tipo de escolha lexical que pode causar desentendimentos é o emprego de palavras ou expressões técnicas, como prova preliminar de sensibilidade e teste de alergia cutânea. Observamos na tabela 3 o mesmo tipo de escolha, como 'lesionado' e 'erupção cutânea'. Caso o 
leitor não conheça essas palavras, eles podem ou inferir um significado errado, que afetará na compreensão da mensagem, ou ignorar a advertência.

A esse respeito, Coulthard (1994) observa que o escritor deve ter em mente que o leitor não possui o mesmo conhecimento linguístico que ele, e por essa razão, o escritor deve criar um Leitor Imaginado e atribuir a ele certo conhecimento. Dessa forma, as escolhas apresentadas acima seriam provavelmente evitadas.

\section{Tabela 2}

\begin{tabular}{|l|l|}
\hline 2) ANVISA & Não usar nos cílios e sobrancelhas; \\
\hline A & Não utilizar para pintar cílios ou sobrancelhas; \\
\hline B & Não usar para pintar cílios ou sobrancelhas; \\
\hline C & $\begin{array}{l}\text { Evitar o contato do produto com a pele e os olhos, não } \\
\text { utilizar para a coloração de cílios e sobrancelhas. Não } \\
\text { seguir estas instruçôes pode levar à cegueira; }\end{array}$ \\
\hline
\end{tabular}

Na Tabela 2, observamos que a ANVISA exige a informação 'Não usar nos cílios e sobrancelhas', que direciona o consumidor a adotar uma medida de segurança. A advertência está clara e precisa, no entanto, ela poderia ser mais eficaz se o risco de não seguir tais instruções fosse apresentado, exatamente como na letra C, 'Não seguir estas instruções pode levar à cegueira'. Devemos ainda ressaltar que o risco mencionado é sério, o que chama mais a atenção para a advertência.

\section{Tabela 3}

\begin{tabular}{|l|l|}
\hline 3) ANVISA & $\begin{array}{l}\text { Não aplicar se o couro cabeludo estiver irritado ou } \\
\text { lesionado; }\end{array}$ \\
\hline A & $\begin{array}{l}\text { Não aplicar se o couro cabeludo estiver irritado ou } \\
\text { lesionado; }\end{array}$ \\
\hline
\end{tabular}




\begin{tabular}{|l|l|}
\hline B & $\begin{array}{l}\text { Não aplicar se tive erupção cutânea na face ou } \\
\text { apresentar o couro cabeludo sensível, irritado ou } \\
\text { lesionado; }\end{array}$ \\
\hline C & $\begin{array}{l}\text { NÃO UTILIZE SE: } \\
\text { - Já apresentou alguma reação alérgica a um produto } \\
\text { de coloração. } \\
\text { - Seu couro cabeludo está irritado ou lesionado. }\end{array}$ \\
\hline
\end{tabular}

O emprego de palavras técnicas aparece novamente nas advertências da Tabela 3, acima, com as palavras 'lesionado' e 'erupção cutânea'. É possível que o consumidor não seja capaz de avaliar caso seu couro cabeludo esteja lesionado ou se há erupções cutâneas em sua pele. Nestes casos, seria importante exemplificar as possíveis lesões, facilitando a avaliação. Além disso, nenhuma delas apresenta o risco, e as medidas que deveriam ser tomadas, caso o risco ocorra.

\section{Tabela 4}

\begin{tabular}{|l|l|}
\hline 4) ANVISA & $\begin{array}{l}\text { Em caso de contato com os olhos, lavar com água } \\
\text { em abundância; }\end{array}$ \\
\hline A & $\begin{array}{l}\text { Evitar o contato com os olhos. Se isto acontecer, } \\
\text { enxaguar com água em abundância imediatamente; }\end{array}$ \\
\hline B & $\begin{array}{l}\text { Em caso de contato com os olhos lavar imediatamente } \\
\text { com água em abundância e procurar um médico; }\end{array}$ \\
\hline C & $\begin{array}{l}\text { Se o produto entrar em contato com os olhos lave } \\
\text { com água em abundância; }\end{array}$ \\
\hline
\end{tabular}

Na Tabela 4, notamos que a advertência orienta a ação do consumidor caso o risco não seja evitado. Novamente sentimos falta do risco em si, o que leva o consumidor a fazer inferências sobre o risco e a gravidade dele. Em B, vemos um acréscimo de informação 'procurar 
um médico', mas, quando um médico deveria ser procurado? Se sentir ardência ou irritação? Se não conseguir enxergar? Já a advertência mostrada na Tabela 5, abaixo, apresenta a mesma deficiência com relação à Tabela 4 , isto é, não menciona o risco. Ademais, seria interessante se constassem as medidas que deveriam ser tomadas caso as crianças entrassem em contato com o produto.

\section{Tabela 5}

\begin{tabular}{|l|l|}
\hline 5) ANVISA & Manter fora do alcance das crianças; \\
\hline A & Mantenha fora do alcance das crianças; \\
\hline B & Mantenha fora do alcance das crianças; \\
\hline C & $\begin{array}{l}\text { Manter fora do alcance das crianças. Não utilizar em } \\
\text { crianças; }\end{array}$ \\
\hline
\end{tabular}

Apesar de as advertências das três marcas analisadas acima estarem em conformidade com os requisitos da ANVISA, notamos que ainda faltam informações, sobretudo em relação aos riscos decorrentes dos produtos. Além disso, notamos que o uso de palavras técnicas e/ ou pouco comuns pode afetar a compreensão, levando os leitores a inferir significados, que muitas vezes podem ser errados. Acreditamos que a ANVISA deveria rever os requisitos, não somente referente às informações, mas principalmente no que tange à forma com que estas informações são transmitidas aos consumidores.

\section{Uma advertência que falhou}

Passemos, agora, à discussão de um caso canadense no qual Coulthard trabalhou recentemente como perito. Isso, com o propósito de identificar se, no referido caso, os textos advertem adequadamente o comprador. Esse caso específico envolve uma série de textos de advertências que o comprador alegou serem desastrosamente inadequados. 
Resulta que um cliente, Clive Maile, comprou uma churrasqueira/ grill a gás móvel, projetada para uso externo, e a instalou dentro de sua casa. O gás que alimentava o grill era conduzido por meio de um tubo flexível ligado a um cilindro de gás localizado fora da casa. Um dia o grill explodiu, e o filho universitário do Sr. Maile sofreu queimaduras de terceiro grau. O Sr. Maile reivindicou uma indenização, mas a empresa recusou, alegando que ele era o único responsável pelo acidente, uma vez que tinha instalado o grill dentro de casa. A empresa alegou, em sua defesa, que o grill tinha sido projetado para uso externo e que havia uma frase explícita a esse respeito anexado ao grill - APARELHO DE COZINHAR EXCLUSIVAMENTE PARA USO EXTERNO. ${ }^{7}$

Coulthard foi contratado para comentar os significados comunicados tanto nas advertências anexadas ao GRILL-BBQ quanto no manual que acompanhava o equipamento. $\mathrm{O}$ ponto em questão era se o Sr. Maile e/ou outro cliente qualquer poderiam ter interpretado os textos de forma a permitir-lhes instalar o aparelho dentro de casa, apesar de a empresa haver pretendido informar que tal ação seria proibida.

\section{Inferência}

Temos de ter em mente como os escritores produzem um texto e como os leitores processam textos desse tipo. Primeiro vamos considerar o(s) escritor(es). Em Coulthard (1994), em um capítulo intitulado "Avaliando textos", foi sugerido que, a fim de compor qualquer tipo de texto, o escritor deve primeiramente criar, pelo menos inconscientemente, um leitor imaginado para quem ele atribui certo conhecimento e certo desconhecimento a respeito do tópico em questão, além de certas habilidades linguísticas e de processamento de texto. Somente depois, tendo isso em mente, o escritor pode construir seu texto.

Um problema comum de comunicação é que o escritor, na verdade, não visualiza com clareza suficiente o leitor imaginado, e

7. Todos os textos desse caso foram escritos em inglês, embora, como o grill era vendido no Canadá, poderiam também ter textos paralelos em francês. 
nesse caso faz suposições inconscientes. Um segundo problema é que saber o que ele pretende que o texto diga. Ele deve assegurar-se que o texto não permita outras interpretações daquelas pretendidas por ele. Um terceiro problema é que textos são na verdade lidos por leitores reais que podem ser significantemente diferentes, em termos de conhecimento e estratégias e habilidades de processamento de texto, dos leitores imaginados do escritor.

Aparentemente, o sr. Maile, sabendo que era possível comprar um GRILL-BBQ para uso interno, (embora, na verdade, este GRILL$\mathrm{BBQ}$ fosse produzido por outro fabricante e não daquele que o $\mathrm{Sr}$, Maile comprou), foi a uma loja onde viu em exibição um GRILL-BBQ do tipo que ele finalmente comprou. Quatro rótulos estavam afixados ao grill. Dois tinham a palavra PERIGO (DANGER) e um terceiro CUIDADO (CAUTION) $;^{8}$

\section{Rótulo 1}

\section{PERIGO}

Nunca armazene um cilindro LP extra (reserva) embaixo ou perto desta churrasqueira. Nunca encha o tanque além de 3/4 do máximo. Pode ocorrer um incêndio causando morte ou ferimentos graves.

Rótulo 2

\section{PERIGO}

GÁS INFLAMÁVEL SOBRE PRESSÃO DO VAZAMENTO DO GAS LIQUEFEITO (LP) PODE CAUSAR INCÊNDIO OU EXPLOSÃO SE ACIONADO, CONTATE O FORNECEDOR DO GÁS (LP) PARA REPAROS OU DESCARTE DESTE CILINDRO OU DE GÁS LP USADO.

Observe-se que esses dois textos estão em conformidade com os requerimentos de Shuy: eles "identificam e descrevem a natureza e o perigo do risco" - fogo e explosão; eles "contam ao leitor como evitá-

8. Nós apresentamos todos os quatro rótulos numerados a fim de facilitar a referência, além disso, nós realçamos em negrito algumas das palavras e frases. 
lo" - instruindo onde não se deve armazenar e/ou usar o cilindro; e eles comunicam estas informações com uma "linguagem clara e inteligível" admirável. O rótulo 3 apresenta algumas diferenças. Vejamos.

\section{Rótulo 3}

\section{CUIDADO}

Use apenas o regulador de pressão do gás fornecido com este aparelho. Este regulador é ajustado para uma pressão de saída de 11,0 polegadas de coluna de água.

Dessa vez, há uma instrução rotulada somente como 'cuidado' (caution), e não há indicação de nenhuma consequência associada ao não cumprimento da instrução. Não há nenhum tipo de advertência sobre quais podem ser os perigos de não usar o regulador de gás fornecido - é perigoso, tem alguma consequência ou a pressão de saída é importante, se não, por que isso é mencionado afinal? Além do mais, e se o comprador ajustar o regulador a uma pressão diferente - o GRILL-BBQ não funcionará ou poderia resultar em fogo ou explosão? Nenhuma resposta é oferecida, mas como é somente um 'cuidado' e não uma 'advertência' e certamente não é algo rotulado como 'perigoso', o leitor poderá legitimamente supor que não se trata de consequências mais graves. Nota-se ainda que estes três rótulos referem-se exclusivamente ao cilindro de gás e não ao GRILL-BBQ. Em outras palavras, o leitor esta sendo explicitamente advertido pra ter cuidado com o perigoso cilindro de gás, mas não é advertido sobre qualquer perigo associado ao GRILL-BBQ.

Rótulo 4

Kirkland Signature, Virco Associates Inc.

145 Brea Canyon Road, Walnut, CA 91789

MODELO No 720-0011, SÉRIE N: GH

TIPO DE GAS: PROPANO, INPUT:73,000 BTU/HR

CERTIFICADO ANSI Z21.58A-1998

APARELHO DE COZINHAR EXCLUSIVAMENTE PARA USO EXTERNO A ser utilizado apenas em espaços exteriores. SE 
INSTALADO DENTRO DE CASA. RETIRE O CILINDRO E DEIXE-O FORA DE CASA.

A churrasqueira não deve ser utilizada quando existirem materiais inflamáveis a menos de $55 \mathrm{~cm}$ do topo, fundo, parte posterior ou lados da churrasqueira. Não coloque este aparelho sob superfícies inflamáveis suspensas sem proteção. Este aparelho de cozinha para uso externo não foi projetado para ser instalado em trailers e/ou barcos.

Pode-se constatar que nem 'perigo' nem 'cuidado' estão ligados ao quarto rótulo. Embora o leitor seja avisado para evitar superfícies inflamáveis e não colocar o aparelho "em trailers e/ou barcos", não há nenhuma tentativa de "identificar e descrever a natureza do perigo ou [qualquer] risco" envolvido. Não há certamente nenhuma referência ao fogo ou explosão e assim, é permitido ao leitor real fazer qualquer inferência com esta informação. Primeiro, parece-nos razoável inferir a partir da informação de não instalar o GRILL-BBQ "em trailers e/ou barcos" que o equipamento precisa ficar imóvel, e segundo, a preocupação com a superfície inflamável sugere que o GRILL-BBQ pode ocasionar 'incêndio', provavelmente devido ao gotejamento de gordura.

Dessa forma vamos, neste ponto, retornar ao eixo principal do argumento da defesa - o rótulo 4 contém a seguinte informação:

CERTIFICADO ANSI Z21.58A-1998

APARELHO DE COZINHAR EXCLUSIVAMENTE PARA USO EXTERNO

Esta observação parece consideravelmente clara, se isolada. Entretanto, o texto seguinte apresenta problemas interpretativos consideráveis. (pontuação como no original):

CERTIFICADO ANSI Z21.58A-1998

APARELHO DE COZINHAR EXCLUSIVAMENTE PARA USO EXTERNO. SE INSTALADO DENTRO DE CASA. RETIRE O CILINDRO E DEIXE-O FORA DE CASA.

Imediatamente após afirmar, aparentemente, que o aparelho é somente para uso externo, o texto contempla o uso interno. O que o leitor real pode fazer para que haja sentido neste paradoxo? Por um lado, ele é 
avisado que o GRILL-BBQ é "somente para uso externo", enquanto que do outro, se ele escolher instala-lo dentro de casa, ele deve deixar o cilindro fora de casa. Com base nas informações dos rótulos 1-3, ele sabe que o perigo está associado ao cilindro - porém não há nenhuma menção de qualquer perigo associado diretamente ao GRILL-BBQ - logo, este conselho parece ser compatível com as advertências anteriores. Mantenha o perigoso cilindro fora de casa, e use o aparelho, que não tem nenhuma associação ao perigo ou [qualquer] risco, dentro de casa.

Desta forma, uma inferência razoável é que, enquanto o GRILL-BBQ foi certificado somente para uso externo, ele pode ser instalado dentro de casa, desde que com certas restrições e precauções: primeiro, o cilindro tem que ser deixado fora de casa, e o leitor sabe, com base nos rótulos 1-3, quão perigoso pode ser o cilindro, então isto parece ser eminentemente sensato; segundo, o texto subsequente sobre superfícies inflamáveis parece agora relevante. Mas não entendemos como um GRILL-BBQ, que estava sendo usado fora de casa, poderia ter problemas com superfícies inflamáveis, mas ambas referências, "superfícies inflamáveis verticais próximas" e "superfícies inflamáveis suspensas sem proteção" dão suporte a inferência anterior, que o equipamento pode mesmo ser instalado dentro de casa.

O GRILL-BBQ foi entregue com uma cópia do manual, no qual o Sr. Maile teria achado na página 3, se ele realmente tivesse lido, uma seção intitulada Localização

Quando achar um local apropriado, leve em conta precauções como, exposição ao vento que estejam próximas à passagem e mantenha as linhas de abastecimento de gás tão próximas quanto possíveis. Coloque o grill somente em área ventilada. Nunca coloque o grill em uma garagem, passagem coberta, galpão ou outra área fechada sem um sistema de ventilação adequado. (o destaque em negrito não faz parte do original)

Qualquer leitor iria naturalmente supor que 'local/coloque', usado três vezes nas frases, iria referir-se ao "local onde o GRILL-BBQ poderia ser usado" e ele iria ser capaz mais uma vez de derivar o fato de que o GRILL-BBQ pode realmente ser usado dentro de casa, uma vez que a "garagem, passagem coberta ou outra área fechada" tenha "um sistema de ventilação adequado". Esta inferência sobre o uso em área fechada é mais uma vez fortalecida por um conselho que consta na página 4 do 
manual "verifique os códigos de construções locais para um método apropriado de instalação" - por que alguém iria se preocupar com códigos de construções se o GRILL-BBQ foi projetado para uso exclusivamente externo?

Próximo ao texto sobre localização há no Manual uma observação adicional "Não instale esta unidade em espaços fechados e inflamáveis!”, que certamente permite ao leitor inferir que ele pode de fato ser instalado em espaços fechados que não são inflamáveis. Se o novo proprietário fosse consultar a "lista final de instalação", uma vez que ele já tenha instalado o GRILL-BBQ, ele iria confirmar o que ele já tinha deduzido - numa séria de advertências convincentes - que são na verdade somente rotuladas como 'cuidado' - e onde consequências explicitas são mencionadas, que nenhum perigo é associado ao GRILL-BBQ, mas, sim, ao cilindro:

\section{CUIDADOS COM CILINDROS DE PROPANO}

a Não armazene cilindro de gás LP sob ou perto deste aparelho b Nunca encha o cilindro além de $80 \%$ da capacidade

c Se as informações em a e b não forem seguidas à risca pode ocasionar fogo causando morte ou ferimentos graves.

Portanto, uma leitura razoavelmente cooperativa de todos os textos que acompanham o GRILL-BBQ é que, contanto que o GRILLBBQ seja instalado, o que implica que ele esteja fixo e não móvel, desde que tenha um sistema de ventilação adequado, que não tenha superfícies inflamáveis verticais próximas ou superfícies inflamáveis suspensas sem proteção, desde que o cilindro permaneça fora de casa, é de fato permitido fazer exatamente o que o Sr. Maile fez.

$\mathrm{O}$ perito incumbido pelo fabricante aceitou que havia sérios problemas de comunicações, incluindo reais faltas de informação nos textos anexados ao GRILL-BBQ e no manual que o acompanhava, mas ele preferiu colocar a responsabilidade de lidar com estes problemas sobre os ombros do leitor/comprador, neste caso no Sr. Maile, ao invés de culpar o escritor do texto e/ou o fabricante e/ou o vendedor do $\mathrm{BBQ}$ - de fato por conta e risco (caveat emptor). 
Coulthard salientou dois pontos principais: primeiro, sobre a localização do GRILL-BBQ. Como pode ser notado acima, na página 3 do manual, na sessão intitulada "colocação do grill - Localização", o texto afirma sem sombra de dúvidas:

Nunca coloque o grill em uma construção, garage, passagens cobertas, GALPÃO ou outra área fechada sem um sistema de ventilação adequado (negrito adicionado)

Qualquer leitura desse texto leva a crer que é uma 'factive' declaração, isto é, está declarando que um sistema de ventilação adequado realmente existe. Na verdade, a resposta do perito da defesa partiu da premissa que não havia sistema adequado disponível na província. Ele estava, dessa forma, admitindo que o manual estava deliberadamente enganando o consumidor - parecendo-nos a semântica Alice no País das Maravilhas:

"Tome um pouco de vinho", a Lebre de Março ofereceu em um tom encorajador. Alice olhou ao redor por sobre a mesa e não havia nada senão chá. "Não tem nenhum mesmo", retrucou a Lebre de Março.

(Aventuras da Alice no país das Maravilhas, Capítulo 7)

Segundo, o perito abordou o significado da oração "Se instalado dentro de casa..." e escreveu:

"A questão levantada é a segunda frase do rótulo, que estava gramaticalmente incorreta e tinha uma palavra que claramente não correspondia com o restante da advertência, "Se instalado dentro de casa, separe o cilindro e o deixe fora de casa". A palavra "instalado" estava claramente fora de lugar e mostrava inconsistência com o restante da advertência. A palavra correta para esta frase seria "armazenado". A frase deveria transmitir a mensagem "se armazenado dentro de casa, separe o cilindro e o deixe fora de casa", da mesma forma com que apareceu no manual por duas vezes. A palavra incorreta foi evidentemente um erro de tradução. Para uma pessoa leiga, a leitura da segunda frase, que é obviamente incompatível com a primeira, provavelmente causaria a releitura, a fim de averiguar seu significado correto". 
Ao fazer este comentário, o perito ignora despreocupadamente o fato de que ele tinha acabado de aceitar que 'instalado' foi usado corretamente na frase seguinte quando notou:

"a última frase da advertência estava explicita... sem margem para que os consumidores façam interpretações erradas...”. "Este aparelho de cozinha para uso externo não foi projetado para ser instalado em trailers e/ou barcos."

Mas o pior se deve ao fato de ele não dar explicações sobre como 'um consumidor leigo', ao ler o texto, pode deduzir que o primeiro 'instalar' deveria ser interpretado como 'armazenar', mas o segundo e muitas outras ocorrências de 'instalar' que aparecem no manual deveriam ser interpretadas de acordo com o significado comum e correto da palavra 'instalar'. Isto é especialmente difícil quando, como notado acima, há uma leitura legitima de duas frases com um contraste entre duas possíveis localidades: "enquanto o GRILL-BBQ pode ser instalado dentro de casa ele não pode ser instalado em um carro móvel ou barco".

Retornamos ao País das Maravilhas quando palavras querem aparentemente dizer o que o escritor ou Perito quer que elas signifiquem.

"Quando eu uso uma palavra," - disse Humpty Dumpty, num tom escarninho, "ela significa exatamente aquilo que eu quero que signifique... nem mais nem menos."

"A questão," ponderou Alice, "é saber se o senhor pode fazer as palavras dizerem coisas diferentes."

"A questão," replicou Humpty Dumpty, "é saber quem é que manda. É só isso."

(Alice no País do Espelho, capítulo 6)

Nenhum leitor comum lê um manual de instruções esperando ter que negociar o significado de palavras decisivas, mesmo se ele notar que os textos em questão se pareçam inglês não nativo, nem deveria ser esperado que ele o faça. Como já mencionado anteriormente. 


\section{Observações finais}

Os textos que acompanhavam o GRILL-BBQ, comprado pelo Sr. Maile, estavam fatalmente falhos. Eles consentiram uma leitura legítima que permitiu a instalação do GRILL-BBQ dentro de casa desde que existisse um sistema de ventilação adequado e que o cilindro permanecesse fora de casa. O Perito de Defesa tentou negar a interpretação de que a empresa estava deliberadamente enganando o cliente, e ainda retificou que qualquer falha de comunicação nos textos era de responsabilidade do leitor e não do escritor. Assim, o Perito estava de fato aceitando que o escritor dos textos tinha falhado no que Shuy (2008:293), já citado acima, aponta como um princípio essencial de compreensão "o escritor não deve delegar ao leitor a tarefa de inferir o significado".

Infelizmente, não foi possível descobrir a reação da Corte em relação à interpretação, que se baseia no conceito de Leitor Real Cooperativo, porque as partes entraram em acordo pouco antes da data em que o julgamento estava para acontecer.

Recebido em: setembro de 2013 Autores convidados para este volume R.M.COULTHARD@bham.ac.uk carolinehagemeyer@hotmail.com

\section{Referências bibliográficas}

Alice no Pais das Maravilhas http://www.ebooksbrasil.org/eLibris/alicep. $\underline{\mathrm{html}}$

BULAhttp://www.medicinanet.com.br/bula/5214/tCylenol_sinus.htm. Acessado em 13/09/2013.

COULTHARD, R. M. An Introduction to Discourse Analysis. London: Longman. C. 2, 1985. 
COULTHARD, R. M. On Analysing and Evaluating Written Text. In: COULTHARD, R. M. (ed.). Advances in Written Text Analysis. London: Routledge, 1994.

DUMAS, B. K. An Analysis of the Adequacy of Federally Mandated Cigarette Package Warnings. In: LEVI, J. N. \& WALKER, A. G. (Eds.). In Language in the Judicial Process. NY: Plenum Press Corp., p. 309-352, 1992.

Consumer Product Warnings: Composition, Identification, and Assessment of Adequacy. In: COULTHARD, M. \& JOHNSON, A. (Eds.). Routledge Handbook of Forensic Linguistics, Oxford and New York: Routledge, p. 365-377, 2010.

INMETRO http://www.inmetro.gov.br/consumidor/produtos/tintura cabelo.asp. Acessado em 12/11/2012.

FRASER, B. Threatening Revisited. Forensic Linguistics 5: p. 157-73, 1998.

HELLIER, E. \& EDWORTHY, J. Signal Words. In: WOGALTER, M. (Ed.) Handbook of Warnings. Lawrence Erlbaum Associates, 2006.

SEARLE, J. R. Speech Acts: An Essay in the Philosophy of Language. Cambridge: Cambridge UP, 1969.

SHUY, R. Warning Labels: Language, Law, and Comprehensibility. American Speech, 65.4, p. 291-303, 1990.

Fighting Over Words: Language and Civil Law Cases. Oxford: Oxford University Press, 2008.

TIERSMA, P. M. The Language and Law of Product Warnings. In: COTTERILL, J. (Ed.) Language in the Legal Process. Houndmills, Basingstoke, Hampshire and New York: Palgrave Macmillan, p. 54-71, 2002.

WOGALTER, M. S, Purpose and Scope of Warning. In: WOGALTER, M. (Ed.) Handbook of Warnings. Lawrence Erlbaum Associates, 2006.

Factors Influencing the Effectiveness of Warnings. In: ZUAGA, H. J. G.; BOERSMA, T. \& HOONHOUT, H. C. M. (Eds.) Visual Information for Everyday Use. Design and Research Perspectives. Taylor and Francis, 1999.

WOGALTER, M. S., JARRARD, S. W. \& SIMPSON, S. N. Influence of Warning Label Signal Words on Perceived Hazard Level, Human Factors, 36(3): p. 547-556, 1994. 


\section{$\underline{\text { ANEXO }}$}

\section{Os Quatro Rótulos em Inglês}

\section{Label 1}

\section{DANGER}

Never store a spare LP cylinder under or near this barbeque. Never fill the tank beyond $3 / 4$ full. A fire causing death or serious injury may occur.

\section{Label 2}

DANGER

FLAMMABLE GAS UNDER PRESSURE LEAKING LP GAS MAY CAUSE A FIRE OR EXPLOSION IF IGNITED

CONTACT LP-GAS SUPPLIER FOR REPAIRS OR DISPOSAL OF THIS CYLINDER OR USED LP-GAS

DO NOT USE OR STORE THIS CYLINDER IN A BUILDING GARAGE OR ENCLOSED AREA

\section{Label 3}

\section{CAUTION}

Use only the gas pressure regulator supplied with this appliance. This regulator is set for an outlet pressure of 11.0 inches water column

\section{Label 4}

Kirkland Signature, Virco Associates Inc.

145 Brea Canyon Road, Walnut, CA 91789

MODEL NO. 720-0011, SERIAL NO: GH

TYPE OF GAS: PROPANE, INPUT:73,000 BTU/HR

CERTIFIED UNDER ANSI Z21.58A-1998

OUTDOOR COOKING APPLIANCE FOR OUTDOOR USE ONLY. IF INSTALLED INDOOR. DETACH AND LEAVE CYLINDER OUTDOORS.

Minimum horizontal clearance to adjacent vertical combustible surfaces, below and extending above top of unit from sides 21 inches from back 21 inches. Do not locate this appliance under overhead-unprotected combustible surfaces. This outdoor cooking gas appliance is not intended to be installed in or on recreational vehicles and/ or boats. 